
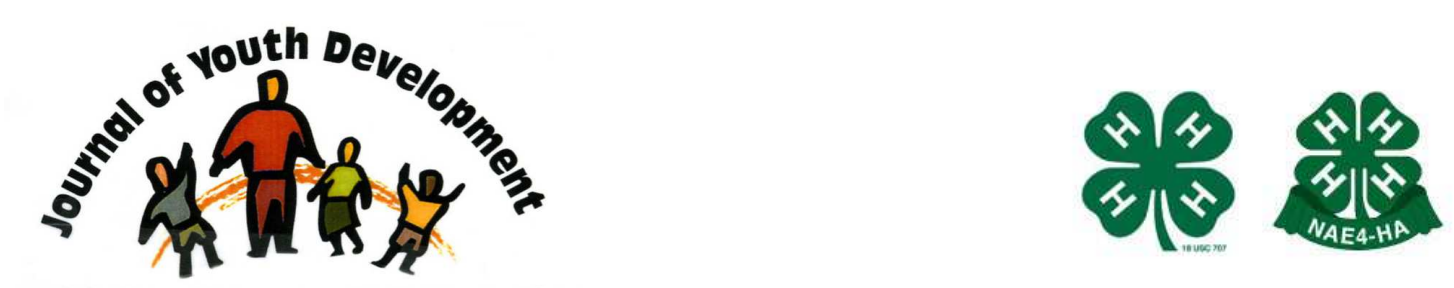

Bridging Research \& Practice

\title{
Promoting Healthy Development among Adolescent Girls: A Mixed-Methods Evaluation of the HERstory Program
}

\author{
Emily MacFarlane \\ New York University
}

Lisa M. Chauveron

The Leadership Program

Amanda C. Thompkins

The Leadership Program

New York, NY

ATHOMPKINS@TLPNYC.COM 


\title{
JOURNAL OF YOUTH DEVELOPMENT \\ bridging research and practice

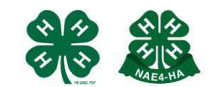

Volume 8, Number 1, Spring 2013

Article 130801PA001

\section{Promoting Healthy Development among Adolescent Girls: A Mixed-Methods Evaluation of the HERstory Program}

\author{
Emily MacFarlane \\ New York University \\ Lisa M. Chauveron and Amanda C. Thompkins \\ The Leadership Program
}

\begin{abstract}
The Leadership Program's HERstory is a school-based, universal, preventative intervention designed to promote healthy youth development among adolescent girls by increasing their connections to pro-social peers and to school and community while developing socialemotional skills that serve as protective factors. In this school-year-long program, a facilitator implements three program phases: group development activities in Community Building, self-reflective Writing Workshop exercises, and a final Creative Output project, an ethnographic theater production or literary journal developed from participants' Writing Workshop responses. The current mixed-methods study presents early evidence of program effectiveness based on focus groups and school record data review at two NYC public schools during the 2010-2011 school year. Participants reported improvements in key areas targeted by HERstory, including peer connectedness, academic achievement, and a range of protective factors including future orientation and goal setting. Results suggest this program approach may be suitable promoting healthy adolescent development for girls.
\end{abstract}

\section{Introduction}

In a society where women continue to lag on social and economic indicators (White House Council on Women and Girls, 2011), providing programs that target young women's academic and social development is critical to promoting positive outcomes for girls. The HERstory program uses participants' creativity in a research-based format to promote such development.

The Leadership Program's HERstory is a school-based preventative intervention designed to promote healthy development for adolescent girls. Its primary foci are building connectedness among participants, and to their schools and communities, and teaching social-emotional skills 
that serve as protective factors. This school-year-long program, developed in-house at The Leadership Program, and implemented by a mentor-style facilitator, is comprised of approximately 60 bi-weekly, two hour meeting sessions. Each session follows a set lesson structure that includes an aim, warm-up, main activity, and closing. Within each segment of the lesson structure, facilitators use the experiential learning cycle (Pfeiffer \& Jones, 1975), a structured sequence of processing designed to accommodate multiple learning styles and social group differences.

The program begins with the Community Building phase, the first of three phases. The initial 12 sessions are group activities designed to promote strong peer networks, a protective factor for girls (Frey \& Röthlisberger, 1999), that guards against academic failure and substance use (Morrison, Brown, D’Incau, et al., 2006; Willis, Resko, Ainette \& Mendoza, 2004). Peer connections that develop in the safety of a single-sex space may lead to deeper bonds between individuals than those occurring in a co-ed environment (Maccoby, 1988).

In the second phase, youth participate in a 14 session Writing Workshop built around seven topical themes. Each thematic section includes an interactive group activity and a structured writing exercise. Creative and self-expressive writing is beneficial for young women as it facilitates the development of their identities, a protective factor (Eccles \& Gootman, 2002; Gardiner, 1981 alpha ). Ordered topically, sections begin with identity exploration (Who Am I?), then expand to include immediate circles of influence (Those You are Closest To) and developmentally relevant topics (Body Image, Love and Relationships). Girls then explore where they come from (Heritage), where they want to go (Dreams), and how they hope to be remembered (Legacy). The activities in the Writing Workshop phase are designed to support participants' intellectual development by targeting critical thinking and reasoning skills and developing cultural competency and social awareness, which are associated with improvements in protective factors such as self-esteem, self-efficacy and identity development (Eccles \& Gootman, 2002). Additionally, many Writing Workshop topics target specific protective factors, such as future orientation (Dreams and Legacy) and positive personal and ethnic identity (Who Am I? and Heritage).

The thematic content generated in the structured writing exercises forms the backbone of the final program phase, Creative Output. During the Creative Output phase, which varies in length from 5 to 20 sessions according to the resources of the facilitating organization, participants work with the facilitator to create their final artistic project, a literary journal or piece of ethnographic theater that allows them to express their thoughts about each theme to their communities.

The Creative Output section helps reinforce the peer connections established in the Community Building section, as group art projects promote teamwork and facilitate inter-group dialogue (Connors, 1998; Cooper \& Sjostrom, 2006). Because HERstory is a school-based program, it also has the potential to improve school connectedness, which Centers for Disease Control (CDC) researchers have identified as the single strongest protective factor against violence, substance abuse, and school absenteeism (CDC, 2009; Resnick, Bearman, Blum et al, 1997; Resnick, Harris, \& Blum, 1993). The Creative Output portion targets school connectedness explicitly by involving teachers, parents, community members, and other youth as audience members for the final theatrical performance, or as attendees at a "book party" unveiling the completed literary journal. Last, participation in the creative process is associated with improvements in protective factors including self-regulation, self-efficacy, and positive identity 
development (Baum, Owen \& Oreck, 1997; Fredricks \& Eccles, 2005; Hetland et al., 2007; Philips, Linington, \& Penman, 1999).

The current mixed methods pilot study was conducted with HERstory participants during the 2010-2011 school year and assesses the relevance of the program theory to participants, as well as the program's effectiveness at promoting protective factors and academic achievement among participants.

\section{Methods}

Study participants were 22 middle (MS) and 25 high school (HS) students from two New York City public schools (one MS, one HS). All participants were regular HERstory attendees during the 2010-2011 school year. The mean age of MS participants was 12.2, HS = 15.4. Participants described themselves as Latina (100\%). Both schools received Title 1 funding, indicating at least $40 \%$ of the student body received free/reduced lunch. Youth at both schools elected to participate in HERstory, however, the high school group began the year at greater risk for academic failure (their starting GPA was considerably lower), and reported histories of incarceration, institutionalization, and gang membership.

A combination of focus groups and school record data review were used to obtain a complete picture of program effectiveness. $17 \mathrm{MS}$ and eight HS youth participated in half-hour focus groups designed to elicit information about improvements in protective factors targeted in the HERstory theoretical model, such as peer and school connectedness, academic performance, and future oreintation and goal setting (see Appendix A). Approximately two hours of recorded focus group conversations were analyzed for theoretically relevant content, including any attitude and behavior changes participants attributed to HERstory.

To further examine the association of participation in HERstory with academic achievement, school record data for all participants were reviewed. We examined whether HERstory participants showed improvements in their English, math, and overall grades and school attendance throughout the school year, by comparing first to last quarter performance.

\section{Results}

\section{Focus groups}

Participants confirmed the relevancy of the program's theoretical model. Across both age groups, youth reported overwhelmingly positive feelings towards the program. Three major themes arose in their answers: increased peer, adult, and school connectedness, increases in academic achievement, and increases in future orientation and goal setting behavior.

Participants reported a high level of connectedness to one another, as one participant reports, "we became a family." When asked what facilitated this level of closeness, participants cited the Community Building group exercises and mutual self-disclosure, "When you get to know someone in HERstory you get to know who they are and how their life is and maybe you have something in common." Youth also reported close ties to their facilitator, describing her as a "mentor," "friend" and "role model."

Participants credited their HERstory support network for changes in their academic performance. One participant reported that: 
"I think that HERstory has made a difference because in the past when you're with teachers you don't want to ask questions because you are shy and embarrassed; but once you come to HERstory if anything bad happens you can always come here and talk about it."

This confidence in the classroom was echoed by other participants who stated, "I used to stay in the back and listen to the teacher, but now I am participating more and I got better grades than last time." Additionally, participants reported being more likely to come to school on days with HERstory meetings; one stated "there are days when I want to leave school but I stay all day for HERstory." They also reported increased confidence with academic writing due to the required HERstory writing exercises.

Last, many participants reported specific goals for their futures and illustrated the ways in which HERstory facilitated goal creation and attainment. One participant said "HERstory makes me feel like if I want to be the first cop in my family I can do it."

\section{School record data}

As mentioned above, MS participants tended to be more successful academically (mean overall $\mathrm{GPA}=82 \%$, english GPA $=85 \%$, math GPA $=84 \%$ ) at the beginning of the school year than HS participants (mean overall GPA $=71 \%$, English GPA $=68 \%$, math GPA $=60 \%$ ).

Patterns of change also differed by age group, as MS youth showed improvements in overall GPA throughout the year (12 youth improved, three declined, seven remain constant; mean final overall GPA $=87 \%$, English $=86 \%$, math $=83 \%$, while HS youth predominately improved their performance in English (10 improved, six declined, nine stayed the same; mean final overall GPA $=67 \%$, English GPA $=70 \%$ math $=65$

\section{Discussion}

Though preliminary in nature, results suggest academic and social-emotional benefits for HERstory participants. Qualitative findings suggest resonant lesson content and that the expected benefits in social-emotional skill building are leading to improvements in participants' risk and protective factor profiles, such as stronger peer support networks, higher levels of school connectedness, improved self-concept and self-efficacy, and a stronger sense of future orientation. Both qualitative and quantitative findings tentatively suggest academic improvements, as expected from improvements in risk and protective factors. Our findings suggest our conceptualization of HERstory's program theory is accurate, and that participation may be beneficial for urban adolescent girls. Future steps include a quasi-experimental quantitative evaluation of program effectiveness that will allow us to investigate causal linkages between program participation and academic performance. 


\section{References}

Baum, S., Owen, S., \& Oreck, B. (1997). Transferring individual self-regulation processes from the arts to academics. Arts Education Policy Review, 98(3), 32-39.

Centers for Disease Control and Prevention. (2009). School connectedness: Strategies for increasing protective factors among youth. Atlanta, GA: U.S. Department of Health and Human Services.

Connors, K.E. (1998). Conflict Resolution \& Recognition of Diversity via an Art Experience. Journal of Art \& Design Education, 17(3), 275-282.

Cooper, M., \& Sjostrom, L.(2006). Making art together: How collaborative art-making can transform kids. Boston, MA: Beacon Press Books.

Eccles, J.S., \& Gootman, J.A. (Eds.). (2002). Community programs to promote positive youth development. Committee on Community-Level Programs for Youth. Board on Children, Youth, and Families, Commission on Behavioral and Social Sciences and Education, National Research Council and Institute of Medicine. Washington, DC: National Academy Press.

Fredricks, J.A., \& Eccles, J.S. (2005). Developmental benefits of extracurricular involvement: Do peer characteristics mediate the link between activities and youth outcomes? Journal of Youth and Adolescence, 34(6), 507-520.

Frey, C.U., \& Röthlisberger, C. (1999). Social support in healthy adolescents. Journal of Youth \& Adolescents, 25(1), 17-31.

Gardiner, J.K. (1981). On female identity and writing by women. Critical Inquiry, 8(2), 347-361.

Hetland, L., Winner, E., Veenema, S., \& Sheridan, K. (2007). Studio thinking: The real benefits of visual arts education. New York, NY: Teacher's College Press.

Maccoby, E.E. (1988). Gender as a social category. Developmental Psychology, 24(6), 755-765.

Morrison, G.M., Brown, M., D’Incau, B., O’Farrell, S.L., \& Furlong, M.J. (2006). Understanding resilience in educational trajectories: Implications for protective possibilities. Psychology in Schools, 43(1), 19-31.

Pfeiffer, J.W., \& Jones, J.E. (1975). Introduction to the structured experiences section. In J.E. Jones \& J.W. Pfeiffer (Eds.), The 1975 annual handbook for group facilitators (pp. 3-5). San Diego, CA: Pfeiffer \& Company.

Philips, D., Linington, L., \& Penman, D. (1999). Creative writing and mental health. London: Jessica Kingsley Publishers.

Resnick, M.D., Bearman, P.S., Blum, R.W., et al. (1997). Protecting adolescents from harm: Findings from the national longitudinal study on adolescents' health. Journal of the American Medical Association, 278(10), 823-832. 
Resnick, M.D. Harris, L.J., \& Blum, R.W. (1993) The impact of caring and connectedness on adolescent health \& well-being, Journal of Paediatrics \& Child Health, 29, Sup1,s3-s9.

White House Council on Women and Girls. (2011). Women in America: Indicators of social and economic well-being. Retrieved 28 April 2011 from:

http://www.whitehouse.gov/sites/default/files/rss viewer/Women in America.pdf

Willis, T.A., Resko, J.A., Ainettte, M.G., \& Mendoza, D. (2004). Role of parent support and peer support in adolescence use: A test of mediated effects. Psychology of Addictive Behaviors, $18(2), 122-134$.

(c) Copyright of Journal of Youth Development Bridging Research and Practice. Content may not be copied or emailed to multiple sites or posted to a listserv without copyright holder's express written permission. However, users may print, download or email articles for individual use. 


\section{Appendix A}

Focus Group Questions

\section{Group dynamics}

1. Buy-in: Do you feel connected to HERstory outside of the designated meeting times? Why?

2. Group cohesion: Do you feel like your HERstory group bonded? What helped that to happen?

a. PROMPT: Do you feel closer to the girls in this group now than before HERstory started?

\section{Protective factors}

3. School connectedness: Do you come to school for often on the days with HERstory or do you look forward to school more on those days?

4. Self-concept: Do you think of yourself differently since participating in HERstory? What about you has changed?

5. Self-efficacy: Do you feel like you are capable of doing more since being in HERstory? What can you do now that you couldn't do before?

6. Future orientation/goal development: How has HERstory helped you to think about your future and your goals? What goals do you have for yourself now that you didn't before?

7. Identification of support network: Who do you go to if you have a problem? Are these people the same ones you would have gone to before the beginning of this school year?

8. (WHIP AROUND): How does it feel to perform your own words for an audience? Is it fun, scary, exciting? Why do you think it feels this way? Please tell me in one word and in one sentence say why you chose that word.

\section{Facilitator's role}

9. What makes (facilitator's name) a good facilitator?

10. How does she help you when you hit a roadblock? i.e., a problem with another participant or when you get stuck trying to answer a writing prompt.

11. Is there anything you wish she did differently? 